\title{
Genetic Discrimination and Health Insurance: An Urgent Need for Reform
}

\author{
20 October 1995, Volume 270, pp. 391- 393 \\ Kathy L. Hudson, Karen H. Rothenberg, Lori B. Andrews, \\ Mary Jo Ellis Kahn, Francis S. Collins
}

The accelerated pace of gene discovery and molecular medicine portend a future in which information about a plethora of disease genes can be readily obtained. As at-risk populations are identified, research can be done to determine effective prevention and treatment strategies that will lower the personal, social and perhaps the financial costs of disease in the future. We all carry genes that predispose to common illnesses. In many circumstances knowing this information can be beneficial, as it allows individualized strategies to be designed to reduce the risk of illness. But, as knowledge about the genetic basis of common disorders grows, so does the potential for discrimination in health insurance coverage for an ever increasing number of Americans.

The use of genetic information to exclude high-risk people from health care by denying coverage or charging prohibitive rates will limit or nullify the anticipated benefits of genetic research. In addition to the real and potentially devastating consequences of being denied health insurance, the fear of discrimination had other undesirable effects. People may be unwilling to participate in research and to share information about their genetic status with their health care providers or family members because of concern about misuse of this information. As genetic research progresses and preventive and treatment strategies are developed, it will be increasingly important that discrimination and the fear of discrimination not be a roadblock to reaping the benefits. To address these issues, the National Institute of Health-Department of Energy (NIH-DOE) Working Group on Ethical, Legal, and Social Implications (ELSI) of the Human Genome Project and the national Action Plan on Breast Cancer have jointly developed a series of recommendations for state and federal policymakers which are presented below.

In the past, genetic information has been used by insurers to discriminate against people. In the early 1970s, some insurance companies denied coverage and charged higher rates to African Americans who were carriers of the gene for sickle cell anemia (1). Contemporary studies have documented cases of genetic discrimination against people who are healthy themselves but who have a gene that predisposes them or their children to a later illness such as Huntington's disease (2). In a recent survey of people with a known genetic condition in the family, $22 \%$ indicated that they had been refused health insurance coverage because of their genetic status, whether they were sick or not (3).

As a case example, Paul (not his real name) is a healthy, active 4-year-old, but he has been twice denied health insurance. Paul's mother died in her sleep of sudden cardiac arrest when Paul was only 5 months old. Paul's maternal uncle also died of sudden cardiac arrest when he was in his twenties. After these sudden and unexpected deaths, Paul's family began to hunt to discover the cause. Their search finally led to a research geneticist who was able to determine that several family members, including Paul and his mother, carried an alteration in a gene on chromosome 7. This gene is one of several genes that cause the long QT syndrome, so-called because of the distinctive diagnostic pattern on an electrocardiogram. 
Several years ago, Paul's father, Bob, lost his job and with it the group policy that provided health insurance coverage for Paul and him. Paul's father has repeatedly applied for a family health insurance policy with a major insurance company. The company agreed to cover Bob but refused to issue a family policy that would cover Paul because he has inherited the altered gene for the long QT syndrome from his mother.

The story of Jackie and Emma further illustrates the social, ethical, and legal dilemmas presented by the revelation of genetic information. Sisters Jackie and Emma, along with many other members of their family, have been tested as part of a research protocol for alterations in the gene BRCA1 that confers hereditary susceptibility to breast and ovarian cancer. Both were offered an opportunity to learn the results of their genetic tests and both accepted. They each learned they carry an altered form of the gene, putting them at increased risk for breast and ovarian cancer.

After finding out the results of her genetic test, Emma had a mammogram that showed a very small lesion in her breast. A subsequent biopsy revealed carcinoma, and Emma decided to proceed with a bilateral mastectomy because of the substantial risk of cancer arising in the opposite breast. Her lymph nodes were negative for cancer, so her prognosis for cure is very good.

Emma's sister Jackie also tested positive for the same alteration in the BRCA1 gene, though no cancer was detected. Although the benefit of prophylactic mastectomy in reducing the risk for breast cancer is not yet known, she decided to have a bilateral prophylactic mastectomy. Emma and Jackie feel strongly that they have benefited from knowing this genetic information but are fearful that it will be used against them and their family by insurers and employers. They both keep their genetic status secret and are so fearful of losing their health insurance that they used assumed names when sharing their story at a recent workshop on genetic discrimination (4).

Emma and Jackie's story is not unique. An estimated 1 in 500 women carry a mutation in the BRCA1 gene that may confer as much at an $85 \%$ chance of breast cancer and a $50 \%$ chance of ovarian cancer (5). Although substantial uncertainty exists about the relative value of the available options (surgery compared with intensive surveillance) for a woman with a BRCA1 mutation, it is likely that ultimately this information will be medically useful.

\section{Health Insurance in the United States}

Because of high costs, insurance is essentially required to have access to health care in the United States. Over 40 million people in the United States are uninsured (6). Group insurance, individual insurance, self-insurance and publicly financed insurance (for example, Medicare and Medicaid) are the principal forms of health insurance in the United States for the $\mathbf{2 4 0}$ million Americans with coverage. Most people get their health insurance through their employer. Many employers provide health insurance coverage though self-funded plans in which the employer, either directly or through a third party, provides health insurance coverage. For individuals and small groups, insurance providers use medical history as well as individual risk factors, such as smoking, to determine whether to provide coverage and under what terms. This is known as underwriting. Insurers argue that underwriting is essentially in a voluntary market to prevent "adverse selection," in which individuals elect not to purchase insurance until they are already ill or anticipate a future need for health care. Insurers fear that individuals will remain uninsured until, for example, they receive a genetic test result indicating a predisposition to some disease such as breast or colon cancer. 
In the absence of the ability to detect hereditary susceptibility to disease, the costs of medical treatment have been absorbed under the current health insurance system of shared risk and shared cost. Today, our understanding of the relation between a misspelling in a gene and future health is still incomplete, thus limiting the ability of insurers to incorporate genetic risks into actuarial calculations of a large scale. As genetic research enhances the ability to predict individuals' future risk of diseases, many Americans may become uninsurable on the basis of genetic information.

\section{State and Federal Initiatives}

A recent survey has shown that a number of states have enacted laws to protect individuals from being denied health insurance on the basis of genetic information (7). The first laws addressing genetic discrimination were quite limited in scope and focused exclusively on discrimination against people with a single genetic trait (8). Since the Human Genome Project was launched in the 1990, eight states have enacted some form of protection against genetic discrimination in health insurance. The recently enacted state laws are not limited to a specific genetic trait but apply potentially to an unlimited number of genetic conditions. These state laws prohibit insurers from denying coverage on the basis of genetic test results, and prohibit the use of this information to establish premiums, charge differential rates, or limit benefits. A few of these states, including Oregon and California, integrate protection against discrimination in insurance practices with privacy protections that prohibit insurers from requesting genetic information and from disclosing genetic information without authorization.

Two factors limit the protection against discrimination afforded by current state laws. First, the federal Employee Retirement Income Security Act exempts self funded plans from state insurance laws. Nationwide, over one-third of the nonelderly insured population obtains health insurance coverage through a self-funded plan. Second, nearly all of the state laws focus narrowly on genetic tests, rather than more broadly on genetic information generated by family history (7). Limiting the scope of protection to results of genetic tests means that insurers are only prohibited from using the results of a chemical test of DNA, or in some cases, the protein product of a gene. But insurers can use other phenotypic indicators, patterns of inheritance of genetic testing as the basis of discrimination.

Meaningful protection against genetic discrimination required that insurers be prohibited from using all information about genes, gene products, or inherited characteristics to deny or limit health insurance coverage.

No federal laws are currently in place to prohibit genetic discrimination in health insurance (9). The Clinton Administration's proposal to reform the health care system and provide health insurance for all Americans did prohibit limiting access or coverage on the basis of "existing medical conditions or genetic predisposition to medical conditions" (10). Congressional efforts to reform the health care system in 1995 have been much more modest and are targeted at guaranteeing access, portability, and renewability of coverage and at leveling the playing field in the insurance market so that the same rules apply to insured and self-funded plans. Recent federal health insurance reform proposals attempt to guarantee the availability of health care by prohibiting insurers from denying coverage on the basis of health status, medical condition, claims experience, or medical history of a participant. Most of the proposals permit exclusions for pre-existing conditions, but these are time limited.

It is not clear if the current health insurance reform proposals would prohibit insurers from denying coverage on the basis of genetic information. Genetic information is distinct from other types of medical information because it provides information about an individual's predisposition to future disease. In addition, genetic information can provide clues to the future health risks for an individual's 
family members. If enacted, current health reform proposals would prohibit denying insurance to those currently suffering from disease or with a past history of disease. But these proposals may not protect people like Paul, who are healthy but have a genetic predisposition to disease, from being refused insurance coverage. Currently proposals also may fail to protect couples who, although healthy themselves, carry the gene for a recessive disorder such as cystic fibrosis that might affect their children or future children.

\section{Recommendations}

Planners of the Human Genome Project recognized from the beginning that maximizing the medical benefits of genome research would require a social environment in which health care consumers were protected from discrimination and stigmatization based on their genetic make-up. Genome programs at both the DOE and the National Center for Human Genome Research, a component of $\mathrm{NIH}$, have each set aside a portion of their research budget to anticipate, analyze, and address the ELDI of new advances in human genetics. The original planners also created the NIH-DOE ELSI Working Group, which has a broad and diverse membership including genome scientist; medical geneticists; experts in law, ethics, and philosophy; and consumers, to explore and propose options for the development of sound professional and public policies related to human genome research and its applications. The ELSI Working Group has long been involved in discussions about the fair use of genetic information. In a 1993 report, "Genetic Information and Health Insurance" (11), the ELSI Working Group recommended a return to the risk-spreading goal of insurance. The Working Group suggested that individuals be given access to health care insurance irrespective of information, including genetic information about their past, current, or future health status. Because denial of insurance coverage for a costly disease such as breast cancer may prove to be a death sentence for many women, the National Action Plan on Breast Cancer (NAPBC), a public-private partnership designed to eradicate breast cancer as a threat to the lives of American women, has indentified genetic discrimination in health insurance as a high priority (12).

Building on their shared concerns, the NAPBC (13) and the ELSI Working Group (14) recently cosponsored a workshop on genetic discrimination and health insurance (4). Scientists, representatives from the insurance industry, and members of the ELSI Working Group and the NAPBC participated in the 1-day session. On the basis of the information presented at the workshop, the ELSI Working Group and the NAPBC developed the following recommendations and definitions for state and federal policymakers to protect against genetic discrimination.

1. Insurance providers should be prohibited from using the genetic information, or an individual's request for genetic services to deny or limit any coverage or establish eligibility, continuation, enrollment, or contribution requirements.

2. Insurance providers should be prohibited from establishing differential rates or premium payments based on genetic information or an individual's request for genetic services.

3. Insurance providers should be prohibited from requesting or requiring collection or disclosure of genetic information.

4. Insurance providers and other holders of genetic information should be prohibited from releasing genetic information without prior written authorization of the individual. Written authorization should be required for each disclosure and include to whom the disclosure would be made. The definitions are as follows.

Genetic information is information about genes, gene products, or inherited characteristics that may derive from the individual or a family member. Insurance provider means an insurance 
company, employer, or any other entity providing a plan of health insurance or health benefits including group or individual health plans whether fully insured or self-funded.

These recommendations have been endorsed by the National Advisory Council for Human Genome Research (NACHGR) (15). The NACHGR stresses the positive value of genetic information for improving the medical care of individual patients and the need to ensure the freedom of patients and their health care providers to use genetic information for patient care. The NACHGR views the elimination of the use of genetic information to discriminate against individuals in their access to health insurance as a critical step toward these goals.

The ability to obtain sensitive genetic information about individuals, families, and even populations raises profound and troubling questions about who will have access to this information and how it will be used. The recommendations presented here for state and federal policy-makers are intended to help ensure that our current social, economic, and health care policies keep pace with both the opportunities and challenges that the new genetics present for understanding the causes of disease and developing new treatment and preventive strategies.

\section{References and Notes}

1. L. Andrews, Medical Genetics: A Legal Frontier (American Bar Foundation, Chicago, IL, 1987).

2. P.R. Billings et al., Am.J. Hum. Genet. 50, 476 (1992).

3. E. V. Lapham (Georgetown University) and J. O. Weiss, The Alliance of Genetic Support Groups, Human Genome Model Project, preliminary results of a survey of persons with a genetic disorder in the family.

4. "Genetic Discrimination and health insurance: A case study on breast cancer," Bethesda, MD, 11 July 1995, workshop sponsored by the National Action Plan on Breast Cancer (NAPBC) and the NIH-DOE Working Group on the Ethical, Legal, and Social Implications of Human Genome Research.

5. D. F. Easton et al., AM. J. Hum. Genet. 52, 678, (1993); D. Ford et al., Lancet 343, 692 (1994).

6. Employee Benefit Research Institute Special Report SR-28, issue brief number 158, February 1995.

7. K.H. Rothenberg, J. Law. Med. Ethics, in press.

8. North Caroline, NC ST: 58-65-70 (1975), Florida, FL ST: 626.9707 (1978). Alabama, AL ST: 275-13 (1982). In 1987, Maryland passed a law, Art. 48A, 223(b)(4), prohibiting health insurers from discrimination in rates based on genetic traits unless there was "actuarial justification."

9. In March 1955, the U.S. Equal Employment Opportunity Commission (EEOC) released official guidance on the definition of the term "disability." The EEOC's guidance clarifies that protection under the Americans with Disability Act ( $A D A$ ) extends to individuals who are discriminated against in employment decisions solely on the basis of genetic information about an individual. For example, an employer who makes an adverse employment decision on the basis of an individual's genetic predisposition to disease, whether because of concerns about insurance costs, productivity, or attendance, is in violation of the ADA because that employer is regarding the individual as disabled. Issuance of the EEOC's guidance is precedent setting; it is the first broad federal protection against the unfair use of genetic information.

10. Health Security Act, Section 1516, S. 1757/HR 3600. 
11. "Genetic information and health insurance; Report of the task force on genetic information and insurance" (NIH-DOE Working Group on the Ethical, Legal, and Social Implications of Human Genome Research, 10 May 1993).

12. The NAPBC has as its mission to reduce the morbidity and mortality from breast cancer and to prevent the disease. Specific goals include the following: (i) to promote a national effort to establish and address priority issues related to breast cancer etiology, early detection, treatment, and prevention; (ii) to promote and foster communication, collaboration, and cooperation among diverse public and private partners: and (iii) to develop strategies, actions, and policies to improve breast cancer awareness, services , and research.

13. NAPBC steering committee: Susan J. Blumenthal (co-chair), Zora Kramer Brown, Doris Browne, Anna K. Chacko, Francis S, Collins, Nancy W. Connell, Kay Dickersin, Arlyne Draper, Nancy Evans, Harmon Eyre, Leslie Ford, Janyce N. Hedetniemi, Mary Jo Ellis Kahn, Amy S. Langer, Susan M. Love, Alan Rabson, Jane Reese-Coulbourne, Irene M. Rich, Barbara K. RImer, Susan Sieber, Edward Sondik, and Francis M. Visco (co-chair). NAPBC hereditary susceptibility working group; Kathleen A calzone, Francis S. Collins (co-chair), Sherman Elias, Linda Finney, Judy E. Garber, Ruthann M. Giusti, Jay R. Harris, Joseph K. Hurd Jr., Mary Jo Ellis Kahn (co-chair), Mary-Claire King, Caryn Lerman, Mary Jane Massie, Paul G.

McDonough, Patricia D. Murphy, Philip D. Noguchi, Barbara K. Rimer, Karen H. Rothenberg, Karen K. Steinberg, and Jill Stopfer.

14. ELSI working group: Betsy Anderson, Lori Andrews (chair), James Bowman (dissenting), David Cox, Troy Duster(vice chair), Rebecca Eisenberg, Beth Fine, Neil Holtzman, Philip Kitcher, Joseph Mclnerney, Jeffrey Murray, Dorothy Nelkin, Rayna Rapp, Marsha Saxton, and Nancy Wexler.

15. NCHGR council members: Anita Allen, Lennette J. Benjamin; David Botstein, R. Daniel Camerini-Otero (dissents with recommendation 3), Ellen W. Clayton , Troy Duster, Leroy E. Hood, David E. Housman, Richard M. Myers, Rodney Rothstein, Diane C. Smith, Lloyd M. Smith, M. Anne Spence, Shirley M. Tilgham, and David Valle. 